\title{
Sosialisasi Masyarakat Mahasiswa KKN 26 UIN SU Medan Bidang Pendidikan dan Moderasi Beragama di Tengah Pandemi Covid-19 di Lingkungan 12 Kec. Medan Maimun Kelurahan Sei Mati
}

\author{
Suheri $^{1 *}$, Fadilah Ika Putri Ginting ${ }^{2}$, Muniruddin ${ }^{3}$ \\ ${ }^{1}$ Universitas Islam Negeri Sumatera Utara Medan, Indonesia \\ ${ }^{2}$ Universitas Islam Negeri Sumatera Utara Medan, Indonesia \\ ${ }^{3}$ Universitas Islam Negeri Sumatera Utara Medan, Indonesia \\ * Corresponding Author. E-mail: ${ }^{1}$ suherieuroliner@gmail.com
}

\begin{tabular}{|l|l|l|}
\hline Receive: 13/05/2021 & Accepted: 23/08/2021 & Published: 01/10/2021
\end{tabular}

\begin{abstract}
Abstrak
Pandemi Covid 19 yang masuk ke Indonesia di awal tahun 2020 tahun lalu memaksa semua lapisan masyarakat untuk bekerja dari rumah, belajar dari rumah yang tidak tahu kapan akan berakhir. Di masa pandemi seperti ini, ditambah lagi dengan Kuliah kerja nyata dari rumah terukur (KKN DR TERUKUR) adalah suatu kegiatan pengintegrasian dari pendidikan dan pengajaran, pengabdian dan penelitian terhadap masyarakat oleh mahasiswa secara nyata berdimensi luas melalui pendekatan interdisipliner, komprehensif, dan lintas sektoral. Sebagai pengabdian kepada masyarakat kkn wajib dilakukan oleh mahasiswa/mahasiswi strata-1 (S1) bagi mahasiswa kkn bertujuan untuk: a) pengalaman kegiatan belajar yang berharga melalui keterlibatan secara langsung di lapangan b) merealisasikan bentuk program kerja yang ada di dalam kampus ke dalam masyarakat; c) membuat masyarakat sadar akan keberadaan mahasiswa di tengah tengah masyarakat yang siap membantu. Hubungan masyarakat kkn 26 di Lingkungan 12 merupakan bentuk kunci tali silaturahmi yang antar mahasiswa kkn dan masyarakat, Tak jarang masyarakat mampu menerima mahasiswa kkn apalagi di kala pandemi kali ini yang membuat masyarakat takut untuk menerima orang dari luar karena wabah yang mematikan ini. Kita tahu sendiri pendidikan di kala pandemi ini menurun sangat drastis di mana semua instansi pendidikan di beberapa kota harus di tutup dan belajar dari rumah. Jadi, fungsi sosialisasi di masyarakat ini sebagai bentuk pendekatan kepada mahasiswa dan masyarakat agar terlibat dalam proses kkn yang dilaksanakan oleh mahasiswa uinsu kelompok 26.
\end{abstract}

Kata Kunci: Covid-19, KKN Terukur, Masyarakat.

\section{Community Outreach for Students of KKN 26 UIN SU Medan in the Field of Religious Education and Moderation in the Midst of the Covid-19 Pandemic in $12 \mathrm{Kec}$. Medan Maimun, Sei Mati Village}

\begin{abstract}
The Covid 19 pandemic that entered Indonesia in early 2020 last year forced all levels of society to work from home, study from home, not knowing when it would end. In times of pandemic like this, coupled with real work lectures from home measured (KKN DR TERUKUR) is an activity of integrating education and teaching, community service and research by students in a real broad dimension through an interdisciplinary, comprehensive, and crosssectoral approach. As community service, community service activities must be carried out by undergraduate students (S1) for community service students, aiming to: a) experience
\end{abstract}


Jurnal Edumaspul, 5 (2), Year 2021- 10

(Suheri, Fadilah Ika Putri Ginting, Muniruddin)

valuable learning activities through direct involvement in the field b) realize the form of work programs that exist on campus into the community ; c) make the public aware of the existence of students in the community who are ready to help. Community relations 26 in Neighborhood 12 is a key form of friendship between kkn students and the community, not infrequently people are able to accept kkn students, especially during this pandemic which makes people afraid to accept people from outside because of this deadly epidemic. We know that education during this pandemic has decreased drastically, where all educational institutions in several cities have to close and learn from home. So, the function of socialization in the community is as a form of approach to students and the community to be involved in the community service process carried out by group 26 UINSU students.

\section{Keywords: Covid-19, Measurable Community Service, Community.}

\section{Pendahuluan}

Kuliah Kerja Nyata (KKN) adalah suatu kegiatan intrakurikuler yang memadukan pelaksanaan tri dharma perguruan tinggi (pendidikan, penelitian, dan pengabdian kepada masyarakat) dengan cara membeirkan kepada mahasiswa pengalaman belajar dan bekerja dalam kegiatan pembangunan masyarakat sebagai wahana penerapan dan pembembangan ilmu dan teknologi yang dilaksanakan di luar kampus dalam waktu mekanisme kerja dan teknologi persyaratan tertentu. Dalam konteks ini adalah kkn secara normal. Namun dikala pandemik karena kkn merupakan salah satu syarat wajib untuk wisuda.

Permasalahan yang terjadi di dalam kkn sekarang adalah ditambah dengan wabahcovid 19 yang masuk ke Indonesia mulai awal maret hingga tidak tahu kapan berakhirnya ini membuat mahasiswa yang sedang susah payah dalam pelaksanaan kkn di tambah lagi dengan satu tantangan yang di mana ini syarat mutlak untuk wisuda. Selain itu dengan kkn ini baik tujuan nya sebelum mahasiswa itu lulus dari kampus, ini adalah gladi resik nya kkn dimana terdapat penelitian didalam nya. Mau itu penelitian kualitatif ataupun tindakan kelas selain itu $\mathrm{kkn}$ dr ini menuntut bukan hanya mahasiswa Dosen pembimbing lapangan memikirkan bagaimana cara agar anak mahasiswanya berkecimpung di dunia masyarakat, membawa citra baik dan meninggalkan kesan yang baik pula guna untuk mahasiswa generasi berikutnya ber kkn. Harap mahasiswa adalah kkn dr ini sebenarnya simple saja, tidak banyak tuntutan dan program kerja mengingat pandemik covid 19 ini.

Selain itu beberapa program kerja dalam $\mathrm{kkn}$ ini harus berlandaskan islam dan pendidikan karena di kelompok 26 ini terdapat
2 program studi tadris ips dan pendidikan islam anak usia dini dengan mengangkat tema "kembali ke desa, benahi desa berlandaskan moderasi beragama dan wahdatul ulum" sesuai dengan tema.

Kata moderasi berasal dari Bahasa Latin moderâtio, yang berarti ke-sedang-an (tidak kelebihan dan tidak kekurangan). Kata itu juga berarti penguasaan diri (dari sikap sangat kelebihan dan kekurangan). Kamus Besar Bahasa Indonesia (KBBI) menyediakan dua pengertian kata moderasi, yakni: 1. pengurangan kekerasan, dan 2. penghindaran keekstreman. Jika dikatakan, "orang itu bersikap moderat", kalimat itu berarti bahwa orang itu bersikap wajar, biasa-biasa saja, dan tidak ekstrem (Shihab, 2019). Sedangkan dalam bahasa Arab, moderasi dikenal dengan kata wasath atau wasathiyah, yang memiliki padanan makna dengan kata tawassuth (tengahtengah), i'tidal (adil), dan tawazun (berimbang). Orang yang menerapkan prinsip wasathiyah bisa disebut wasith. Dalam bahasa Arab pula, kata wasathiyah diartikan sebagai "pilihan terbaik". Apa pun kata yang dipakai, semuanya menyiratkan satu makna yang sama, yakni adil, yang dalam konteks ini berarti memilih posisi jalan tengah di antara berbagai pilihan ekstrem. Kata wasith bahkan sudah diserap ke dalam bahasa Indonesia menjadi kata 'wasit' yang memiliki tiga pengertian, yaitu: 1) penengah, perantara (misalnya dalam perdagangan, bisnis); 2) pelerai (pemisah, pendamai) antara yang berselisih; dan 3) pemimpin di pertandingan (Achmadi, 2005; Toto, 2011). 
Jurnal Edumaspul, 5 (2), Year 2021- 11

(Suheri, Fadilah Ika Putri Ginting, Muniruddin)

\section{Metode}

\section{Pendekatan dan Metode Penelitian}

Metode penelitian yang kami lakukan dalam pelaksanaan $\mathrm{kkn}$ ini ada dua penelitian yang pertama adalah dengan pendekatan penelitian kualitatif dimana penelitian kualitatif itu sendiri berbeda dengan penelitian lainnya.dimana penelitian kualitatif ini merupakan metode yang lebih sering di lakukan ketika turun langsung ke lapangan dengan menggunakan beberapa langkah penelitian Metode penelitian kualitatif adalah sebagai metode ilmiah sering digunakan dan dilaksanakan oleh sekelompok peneliti dalam bidang ilmu sosial, antropologi dan sejumlah penelitian perilaku lainnya termasuk ilmu pendidikan. Penelitian kualitatif di bidang sosialisasi kemasyatakatan tidak dilaksanakan di laboratorium tetapi di lapangan tempat peristiwa pendidikan berlangsung secara natural atau alami (Assingkily, 2021).

Selain metode penelitian kualitatif kami menggunakan metode penelitian tindakan kelas dalam pelaksanaan bidang pendidikan di mana penelitian tindakan kelas yang sudah kami pelajari tentang bagaimana pengelolaan kelas dengan baik, fungsi susunan bangku dalam menentukan tempat duduk sudah di terapkan dalam kegiatan KKN kali ini dengan memfokuskan ke 1 anak yang belum sekolah guna pembekalan dia saat mendaftar di jenjang pendidikan formal dan sudah mendapat asupan pelajaran dari pendidikan nonformal yang di selenggarakan $\mathrm{kkn}$ dr uinsu kelompok 26 di tambah lagi yang sudah sekolah karena pandemic jadi lupa bagaimana cara penyelesaian matematika, mulai lupa dengan cara mengeja dan baca jadi di penelitian tindakan kelas kami berusaha mengingat kembali pelajaran yang sudah hampir lupa.

\section{Latar Penelitian}

Dalam observasi, mahasiswa KKN DR kelompok 26 melakukan penelitian langsung kelapangan di Lingkungan $12 \mathrm{Kec}$. Medan Maimoon Kelurahan Sei Mati untuk melihat langsung kondisi pendidikan dan moderasi beragama sehingga dengan adanya observasi tersebut mahasiswa KKN DR UINSU kelompok 26 tahu dan dapat menyusun program kerja yang akan dibuat sesuai dengan kebutuhan di lingkungan tersebut.

\section{Sumber Data dan Teknik Pengumpulan Data}

Menurut Moleong data utama dalam penelitian kualitatif adalah kata-kata dan tindakan, selebihnya adalah data tambahan seperti dokumen dan lain-lain (Moleong, 2013).

Teknik pengumpulan data kualitatif ada 2 yaitu:

1. Data Primer

Data primer adalah data yang langsung didapatkan dari lapangan melalui proses observasi dalam penelitian langsung ini data primer didapatkan dari Kepala Kelurahan Sei Mati Bapak Fahrul Riza SH dan Pengurus Sanggar Anak Sungai Deli Bapak Lukman Hakim Siagian melalui proses wawancara.

2. Data Sekunder

Data sekunder adalah data yang diperoleh secara tidak langsung data sekunder yang kami peroleh secara tidak langsung adalah jumlah penduduk Lingkungan 12 Kec. Medan Maimoon Kelurahan Sei Mati.

\section{Alat Pengumpulan Data}

Alat pengumpulan data adalah teknik dalam mengumpulkan data yang akan dituliskan dalam laporan penelitian berupa:

a) Wawancara adalah kegiatan Tanya jawab dengan informan guna mendapatkan informasi langsung. Informan kunci dalam penelitian kkn ini adalah bapak Fahrul Rozi SH dan Informan Utama nya Bapak Lukman Hakim Siagian sebagai founder dari Sanggar Anak Sungai Deli.

b) Observasi yaitu pengamatan secara intensif dan langsung selama penelitian dan riset lapangan guna untuk membuktikan kebenaran dari kedua informan kunci maupun utama.

c) Studi dokumentasi.

d) Menyiapkan data dalam table atau program kerja agar mudah mempresentasikan nya di lapangan 
Jurnal Edumaspul, 5 (2), Year 2021- 12

(Suheri, Fadilah Ika Putri Ginting, Muniruddin)

\section{Hasil dan Pembahasan}

Hubungan masyarakat dan sosialisasi masyarakat yang dilakukan mahasiswa kkn uinsu kelompok 26 mulai tanggal 10 JULI 2021-10 agustus 2021 seluruh mahasiswa mahasiswi melaksanakan yang namanya KKN DR TERUKUR (Kuliah Kerja Nyata dari rumah terukur) dimana setiap mahasiswa di kelompokkan menjadi beberapa kelompok dengan tembus 6000 peserta secara umum kkn sendiri mempunyai tujuan sendiri seperti:

1. Keterlibatan dalam masyarakat secara langsung, menemukan, merumuskan, memecahkan dan menanggulangi masalah pembangunan secara pragmatis.

2. Mahasiswa dapat perfikir secara kritis berdasarkan ilmu, dan seni guna mempersiapkan kader kader pembangunan.

3. Meningkatkan hubungan baik antara perguruan tinggi dan lembaga pemerintah.

4. Perguruan tinggi memperoleh umpan balik dari masukan yang dapat berguna untuk meningkatkan relevansi pendidikan dan penelitian.

Sebelum melakukan kegiatan selama sebulan penuh di Kec. Medan Maimoon lingkungan 12 kelurahan sei mati kami dan beberapa devisi melakukan hubungan sosial dengan beberapa instansi seperti kelurahan dan pengurus sanggar tepat di tanggal 10 juli 2021 setelah pelepasan kkn yang di buka oleh bapak Dr. Hasan Sazali Ma dengan membawa beberapa dokumen perizinan dan program kerja yang akan di presentasikan dengan kelurahan dan pengurus sanggar anak sungai deli. Setelah melakukan pendekatan dan kesepakatan dengan peserta kkn. Sebelum kami melakukan penelitian kkn kami melakukan sosialisasi kepada masyarakat di hari jumat 16 juli dengan kegiatan gotong royong kami memperkenalkan diri dan kampus serta tujuan kami untuk datang ke tempat itu ngapain, setelah melakukan sosialisasi ke masyarakat kami memohon untuk membantu dan bekerja sama dengan mahasiswa kkn untuk mempercayai anak anaknya belajar dan mengembangkan bakat nya dengan mahasiswa. Tidak hanya itu para peserta kkn juga mensosialisasikan covid ke persimpangan jalan dengan menggunakan masker yang baik selain itu bukan hanya mensosialisasikan menggunakan masker yang baik mahasiswa uinsu membagikan masker sesuai anjuran pemerintah secara garis dan beberapa masyarakat sangat antusias dalam pembagian masker di pinggir jalan karena yang lebih mendominasi nya adalah bapak bapak ojek online dan di bantu bapak kepolisian lalu lintas simpang juanda jln bridgen katamso medan. Dan tidak lupa karena banyak melibatkan anak anak kami juga memberikan makanan dan minuman yang di amanahkan oleh sanggar anak sungai deli.

Kegiatan berjalan satu bulan penuh dengan terjun kelapangan selama $2-3$ hari sekali dengan menerapkan protokol kesehatan kendalanya disini sesuai anjuran lembaga penelitian dan pengabdian masyarakat untuk tidak memiliki posko sangat lelah bagi kami untuk pulang pergi namun antusian peserta $\mathrm{kkn}$ tidak padam begitu saja di hari minggu 18 juli seluruh mahasiswa kkn dapat hadir untuk pembukaan dan pembekalan kkn oleh bapak ucok purba sebagai perwakilan kelurahan, pelepasan mahasiswa $\mathrm{kkn}$ untuk kegiatan gotong royong dan pembuatan ekobrik,dimana ekobrik ini sendiri adalah persamaan dari batu bata CumaEkobrick sendiri adalah botol plastic yang di kemas dengan kepadatan yang ditentukan berfungsi untuk membuat blok bangunan tidak lupa setiap kegiatan gotong royong untuk memberikan apresiasi terhadap orang yang terlibat kami peserta kkn membuat mie goreng yang akan di bagikan kepada masyarakat tak lupa peserta kkn dan pengurus sanggar anak sungai deli juga menikmati mie goreng yang kami buat dengan salah satu masyarakat yang bersedia dapurnya dipakai.

Untuk menyambut hari anak nasional yang jatuh pada tanggal 23 juli 2021 mahasiswa kkn dan sanggar anak sungai deli membuat satu event sesuai dengan tema "Festifal Hari anak" untuk persiapan festifal hari anak sendiri ketua $\mathrm{kkn}$ dan devisi humas $\mathrm{kkn}$ untuk hadir membicarakan festifal tersebut. Final di tanggal 22 juli 2021 saya dan rekan saya fadilah ika putri melihat susunan acaranya, pengenalan panitia perlombaan danmenentukan lomba yang akan di lakukan terdiri dari lomba fashion show, adzan, hafalan surah pendek, berenang, batu serimbang dan mewarnai.

Penyambutan hari anak di mulai ditanggal 24 juli 2021 oleh KKN 26 X 
SASUDE dimana mahasiswa di bagi 2 sift pagi dan siang agar tidak terlalu berkerumun. Lomba di mulai di pukul 10.00 pagi dimulai dengan beberapa sambutan dari sasude, kkn kelompok 26 dan paling di tunggu adalah pawai hari anak,dimana anak anak yang terlibat di festival hari anak tersebut membawa selembar surat yang akan di berikan ke orang tuanya. Surat tersebut berisi 10 hak anak yang harus di dapat. Isi suratnya seperti ini: "selamat hari anak nasional". 10 hari anak yang harus anak anak dapatkan adalah:

1) Bermain

2) Pendidikan

3) Perlindungan

4) Nama

5) Kebangsaan

6) Makanan

7) Kesehatan

8) Rekreasi

9) Persamaan

10) Peran dalam pembangunan

Setelah pawai hari anak berlangsung maka kegiatan selanjutnya adalah acara keagamaan dimana lomba keagamaan ada lomba adzan yang diikuti oleh anak umur 6-12 tahun laki laki dan lomba surah pendek dengan umur dan gender bebas agar anak dapat menguasai minat dan bakatnya. Festival berjalan dengan lancar dengan tetap menggunakan protokol kesehatan di mana devisi kesehatamn masyarakat dengan sigap membagikan masker kepada rekan-rekan dan anak anak yang terlibat di festival tersebut. Lalu dilanjutkan dengan berbagai lomba yang sudah disusun seperti fashion show, berenang, batu serimbang berjalan dengan lancar.

Dengan adanya lomba yang kami lakukan diharapkan anak anak dapat menggali potensi nya lebih baik lagi walaupun kekhawatiran kami karena kami tidak memiliki posko dan keterbatasan ruang kami mengira untuk perlombaan anak anak itu tidak ada di luar ekspektasi ternyata di luar dugaan masyarakat dan anak anak sangat antusias dalam pelaksanaan lomba yang diadakan oleh KKN 26 dan Sasude. Tidak hanya perlombaan seperti kkn yang lainnya kegiatan pendidikan non formal juga di laksanakan kkn dr 26 dengan melibatkan anak anak yang mulai lupa dalam pengerjaan matematika perkalian ke bawah, bahkan baca tulis di kelas 2 SD menjadi perhatian kami. Karena di masa pendemi ini instansi pendidikan benar-benar ditutup secara rapat untuk kegiatan tatap muka. Selama seminggu full kami melaksanakan kegiatan belajar mengajar dan maghrib mengaji dan Alhamdulillah lagi lagi respon anak anak juga baik dalam belajar dan mengaji untuk kegiatan belajar mengajar.

Selama kegiatan $\mathrm{kkn}$ berlangsung Kegiatan berjalan dengan lancar anak-anak mengikuti perlombaan dengan baik dan ikut dalam kegiatan belajar mengajar serta maghrib mengaji dan kami juga bisa melakukan hubungan sosialisasi dengan orang tua mereka sehingga timbulnya suatu komunikasi yang baik antara mahasiswa KKN 26 UINSU dengan masyarakat Lingkungan $12 \mathrm{Kec}$. Medan Maimun Kelurahan Sei Mati.

\section{Simpulan}

Wabah covid memang meresahkan di semua lembaga lapisan masyarakat, dimana masyarakat dibatasi untuk melakukan kegiatannya, WFH, e-learning dimana masyarakat kelas bawah akan kesusahan, disimpulan ini penulis ingin menyampaikan dengan adanya KKN DR ini akan membuat masyarakat tetap semangat dalam melakukan kegiatan, anak anaktidak putus sekolah kepada pemerintah juga yang sudah berjuang untuk rakyat memikirkan kesejahteraan rakyat terimakasih pak, buk karena telah mimikirkan rakyat, semoga $\mathrm{kkn}$ berikutnya sudah melakukan kkn sebenar benarnya kkn yang full sebulan melaksanakan $\mathrm{kkn}$ nya dilapangan sehinggga kita semua dapat belajar dengan nyata. Selain itu dengan adanya kkn ini untuk meningkatkan mutu pembelajaran dan pendidikan bukan hal yang mudah tapi dengan niat awal yang tulus kita dapat merubah perlahan pendidikan di masa pandemi kali ini.

\section{Daftar Pustaka}

[1] Absori. (2006). Pilihan Model Penyelesaian Sengketa Lingkungan Hidup: Studi Manifestasi Kekuatan Otonomi Masyarakat dalam Melakukan Pilihan Model Penyelesaian Sengketa Lingkungan Hidup. Tesis. Diponegoro: 
Undip.

http://eprints.undip.ac.id/28150/.

[2] Achmadi. (2005). Ideologi Pendidikan Islam. Yogyakarta: Pustaka Pelajar.

[3] Assingkily, Muhammad Shaleh. (2021). Penelitian Tindakan Kelas. Medan: CV. Pusdikra Mitra Jaya.

[4] Black, Henry Campbell. (1999). Black's Law Dictionary, edisi VI. St. Paul Minoseta: West Publishing.

[5] Moleong, Lexy J. (2013). Metodologi Penelitian Kualitatif, edisi Revisi. Bandung: PT. Remaja Rosdakarya.

[6] Shihab, M. Quraish. (2019). Washatiyyah Wawasan Islam tentang Moderasi Beragama. Jakarta: Lentera Hati.

[7] Suharto, Toto. (2011). Filsafat Pendidikan Islam. Yogyakarta: Ar-Ruzz Media.

\section{Profil Penulis 1}

Suheri lahir di Belawan, 18 Maret 2000 yang memiliki riwayat pendidikan TK Karya Ibu yang tamat di tahun 2005. Lalu melanjutkan pendidikan sekolah dasar di SD Negeri 064003 Belawan. Tahun 20062012 melanjutkan pendidikannya di SMP Negeri 39 Medan tahun 2012-2015 dan melanjutkan SMA negerinya di SMA Negeri 19 Medan tahun 2015-2018 dan sekarang sedang melanjutkan pendidikan nya di perguruan tinggi negeri. Universitas
Islam Negeri Sumatera Utara Jurusan Tadris ilmu pengetahuan sosial.

\section{Profil Penulis 2}

Fadillah Ika Putri Ginting lahir di Medan, 02 April 2000. Pernah menempuh pendidikan jenjang sekolah dasar di SD Negeri 064987 dan tamat pada tahun 2012. Lalu melanjutkan pendidikan jenjang sekolah menengah pertama di MTsN 1 Medan dan lulus pada tahun 2015. Selanjutnya, menempuh pendidikan jenjang sekolah menengah atas di SMK Negeri 1 Medan dan lulus pada tahun 2018. Dan sekarang sedang melaksanakan pendidikan di UIN Sumatera Utara Medan di jurusan Pendidikan Ilmu Pengetahuan Sosial.

\section{Profil Penulis 3}

Muniruddin lahir di negeri lama 01 Desember 1964 merupakan seorang dosen fakultas dakwah dan komunikasi dan menjadi dosen pembimbing lapangan kelompok 26 yang memiliki riwayat pendidikan SD negeri 112188 negeri Lama tamat tahun 1979 Madrasah ibtidaiyah Al Ittihad Wathaniyah negeri lama tamat tahun 1978 lalu melanjutkan pendidikan nya di Mts swasta gaya baru negeri lama tamat di tahun 1982 lalu melanjutkan pendidikan ke bangku MAN MEDAN fillial tanjung balai di tahun tamat 1985 Melanjutkan pendidikan: (1) S-1 di fakultas syari'ah/PM/IAIN su Medan yg tamat tahun 1990; (2) S-2 Pascasarjana DAPI IAIN SU TAHUN 2003; (3) S-3 fdk/KPI/UINSU tamat tahun 2020 . 